\title{
Matematik Öğretiminde Öğretmen Yeterliliklerinin Bazı Özellikler Açısından İncelenmesi: Betimsel Bir Analiz
}

\section{Kamil AKBAYIR ${ }^{* *}$ ve Aykan AKÇA***}

Öz: Matematik ve sınıf öğretmenlerinin matematik gelişimi ve yeterliliklerinin ne durumda olduğu merak edilmesi gereken önemli bir konudur. Son yıllarda bütün akademik alanlara ilişkin olarak literatür incelemelerinin arttığı görülmektedir. Bu çalışmanın amacı, matematik öğretiminde öğretmen yeterliliklerinin ne durumda olduğunu araştırmaktır. Ayrıca, öğretmen yeterlilik alanlarını incelemek, öğretmenlerin mesleki gelişimlerine katkıda bulunmak, dolayısıyla öğrencilerin matematik başarısına pozitif etkide bulunmak, farkındalık oluşturmaktır. Araştırma verilerini toplamak için örneklem dâhilinde yurt dışında ve yurt içinde matematik öğretiminde öğretmen yeterliliklerinin araştırılması konulu çeşitli tarihlerde yayınlanmış hakemli dergilerdeki makaleler, kitaplar ve tezler araştırma konusu çerçevesinde değerlendirilmiştir. Betimsel analiz ile veriler çözümlenmiştir. Araştırmanın sonuçlarına göre öğretmenlerin başarılı bir eğitim-öğretim süreci yaşayabilmeleri kendi öz-yeterlik inançlarına bağlıdır. Öğretmen öz-yeterlik inancı konusunda yapılan araştırmalar incelendiğinde, özyeterlik inancı yüksek olan öğretmenlerin, daha planlı, düzenli ve bilinçli oldukları, öğrencilerin gereksinimlerini karşılamaya yönelik yeni yaklaşımlar aramaya istekli oldukları, sınıf yönetiminde olumlu yaklaşımlar kullandıkları, öğrenci başarısını ve motivasyonunu yüksek tutabilmekte daha başarılı oldukları ifade edilmektedir.

Anahtar Kelimeler: Matematik öğretimi, Öğretmen yeterlilikleri, Öğrencinin matematik başarısı.

\section{Examining Teacher Competencies in Mathematics Teaching in Terms of Some Features:}

\section{A Descriptive Analysis}

Abstract: The state of math development and competencies of mathematics and classroom teachers is an important issue that should be wondered. In recent years, it is seen that literature

\footnotetext{
* Bu araştırma, Aykan AKÇA’nın yükssek lisans seminerinden üretilmiştir.

**. Dr. Öğrt. Üyesi, Yüzüncü Yıl Üniversitesi, Eğitim Fakültesi, Matematik ve Fen BilimleriEğitim Bölümü, Van, Türkiye, Email: kamilakbayir@gmail.com Orcid No: 0000-0002-7004-8849.

***. Öğretmen, Mevlana Ortaokulu, Van, Türkiye, Email: minelvan65@gmail.com, Orcid No: 0000-0003-0946-2626.
}

Gönderim:13.07.2020 Kabul:25.12.2020 Yayın:15.01.2021


reviews on all academic fields have increased. The aim of this study is to investigate the status of teacher competencies in teaching mathematics. In addition, to examine teacher competency areas, to contribute to the professional development of teachers, thus to have a positive effect on students' mathematics achievement and to raise awareness. In order to collect research data, articles, books and theses published in refereed journals on researching teacher competencies in mathematics teaching abroad and domestically were evaluated within the scope of the research subject. Data were analyzed with descriptive analysis. According to the results of the research, teachers' ability to experience a successful education and training process depends on their own self-efficacy beliefs. When the studies on teacher self-efficacy beliefs are examined, teachers with high self-efficacy beliefs are more planned, organized and conscious, they are willing to seek new approaches to meet the needs of students, use positive approaches in classroom management, and are more successful in keeping student success and motivation high They are expressed.

Keywords: Mathematics teaching, Teacher competencies, Student's mathematics achievement.

\section{Giriş}

Matematik, kişilerin zihinsel gelişimlerini arttırmanın ve dünyayı tanımanın en etkili malzemelerinden biri olarak gözlemlenmektedir. Matematik bilimiyle meşgul olan kişilere temel matematik kavramlarını kavratmanın yanı sıra matematiksel düşünebilme, problem çözebilme, mantıklı muhakemede yapabilme, etkili kararlar alabilme ve matematiği günlük hayatla ilişkilendirebilme gibi beceriler kazandırmaktadır (Milli Eğitim Bakanlığı (MEB), 2018). Bundan dolayı matematiğe, tüm öğretim aşamalarında yer verilmekte ve yapılan reform araştırmalarında matematiğin etkili bir şekilde öğretilmesinin önemi ifade edilmektedir (Franke \& Kazemi, 2001; Gürbüz, Erdem ve Gülburnu, 2013; Smith, 2000).

Öğrencilerin, matematik başarısını etkileyen nedenler en genel şekilde Şekil-1'de gösterilmiştir.

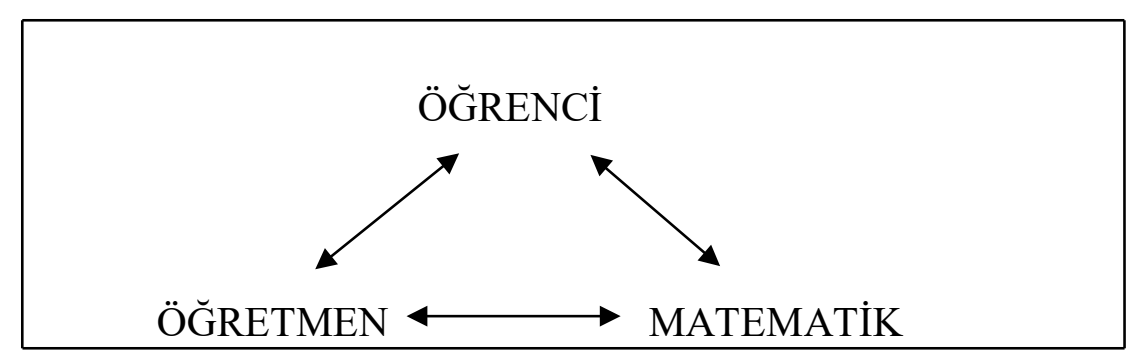

Şekil-1: Öğretmen, öğrenci ve matematik arasındaki ilişkiler (Dursun ve Dede, 2004) 
Görüldüğü üzere üç ana nedenlerden biri “öğretmendir” dir. Öğretmen, öğrenmeyi güdüleyen ve sağlayan kişidir. (Fidan ve Erden, 1994). Eğitim kurumunun, öğretme-öğrenme ilişkisi içinde doğal olarak ortaya çıkmış ilk eğitim mesleği öğretmenliktir (Başaran, 1994). Öğretmenlik, 1739 sayılı Millî Eğitim Temel Kanunun 43. maddesinde şöyle tanımlanmıştır; "Devletin eğitim, öğretim ve bununla ilgili yönetim görevlerini üzerine alan özel bir ihtisas mesleğidir."

Eğitim-öğretim; öğrenci, öğretmen, amaç, konu, metot ve çevre öğelerinin bulunduğu bir ortamda, bunların karşılıklı etkileşimleriyle oluşmaktadır. İyi bir öğretim bunların birbirleriyle uyumlu ve işbirliği içinde yürütülmesi ile mümkündür (Büyükkaragöz ve Çivi, 1999). Görüldüğü gibi eğitim sistemleri toplumun bütününü içine alan birçok unsurdan meydana gelmiştir. Fakat öğretmen, sistemin merkezinde yer almaktadır, çünkü eğitimde amaçların gerçekleşmesi, büyük oranda öğretmenin sınıftaki performansına bağlıdır (Baloğlu, 2001). Öğretmenler, bu görevlerini Türk Millî Eğitimi’nin amaçlarına ve temel ilkelerine uygun olarak yerine getirmekle yükümlüdürler (Ataünal, 2000).

Öğretim süreci ciddi bir faaliyettir ve bu faaliyet sırasında nelerin hangi sira ile ve ne zaman yapılması gerektiği mühimdir.

Öğretim; derin bilgiye sahip olmayı, bu bilgiyi değişen koşullarda sentezleme, bütünleştirme ve farklı grup ve kişiler karşısında kullanabilmeyi gerektiren çok yönlü ve karmaşık bir süreçtir (Gürbüz, Erdem ve Gülburnu, 2013; Hollins, 2011). Bu sürecin etkili yürütülmesi öğrencilerin matematik öğrenmelerini direkt etkilemektedir. Öğrencilerin matematik öğrenmelerinde, sosyo-ekonomik seviye, kültür, dil gelişimi ve öğrenme ortamı gibi birçok faktör sebep olmaktadır (Meece, 1996; Papanastasiou, 2002 akt. Gürbüz, Erdem ve Gülburnu, 2013). Matematiğin öğretim biçimi de, bu kategoriye eklenmesi gereken mühim bir faktördür. Çünkü bir bireyin matematiğe bakışı, o bireyin matematiği nasıl öğrendiği ile alakalıdır (Hare, 1999). Fakat öğrencinin matematik öğrenmesine etki eden en mühim faktörün öğretmen yeterliği olduğu ifade edilmektedir (National Council of Teachers of Mathematics (NCTM), 2000; Romberg \& Carpenter, 1986 akt. Gürbüz, Erdem ve Gülburnu, 2013). Çünkü matematikte, öğretilecek bilgi kadar bu bilginin nasıl öğretileceğinin de mühim olduğu ifade edilmektedir (Gürbüz, Erdem ve Gülburnu, 2013; NCTM, 1989). Nitekim literatürde, öğretmen yeterliği faktörünün öğrencilerin öğrenmelerinde mühim rol oynadığını belirten araştırmalara rastlamak mümkündür (Çakan, 2004; Demir ve Bozkurt, 2011; Dursun ve Dede; 2004; Gürbüz, Erdem ve Gülburnu, 2013; Hacı̈meroğlu ve Şahin, 2011; Rosenholtz, 1985; Seferoğlu, 2001). 
Bilgi, birikimli olarak devam ettiği için öğrencilerin bir sonraki öğrenim aşamalarında başarılı olabilmeleri, ilkokul aşamasında sağlam bir temele sahip olmalarıyla mümkündür. $\mathrm{Bu}$ durum, sınıf öğretmenlerinin yeterliklerinin önemini arttırmaktadır (Gürbüz, Erdem ve Gülburnu, 2013). Yüksek Öğretim Kurumu (1998)’nun yaptığı program değişikliklerinde özellikle Sınıf Öğretmenliği Lisans Program'larına önem verilmesi bu öneminden dolayıdır.

Öğretmen yeterliliği; genel olarak alan bilgisi, pedagojik alan bilgisi, materyal ve programların dahil olduğu müfredat bilgisi, sınıf yönetimi ve organizasyonu bilgilerini içine alan pedagoji bilgisi, öğrenci ve özelliği bilgisi, eğitim ortamı ve şartları bilgisi, eğitim ile ilgili amaçlar, hedefler ve değerler ile bunların felsefi ve tarihsel temelleri bilgisi şeklinde sınıflandırılmıştır (Gürbüz, Erdem ve Gülburnu, 2013; Shulman, 1987). Bunlardan ilk ikisi öğretmenin özel alan yeterlikleri kapsamında değerlendirilmektedir.

Matematik öğretmeni olabilmek için, öğretmen adayları güçlü bir alan bilgisi, alana özgü pedagoji bilgisi ve öğrencilerin zihinsel gelişimleri bilgisine hâkim olmalıdırlar (Ball, 1990; Carpenter Vd., 1996; Ma, 1999; Shulman, 1986; Toluk-Uçar, 2010). Bu üç bilgi türü öğretmenin öğretimini planlarken ve tatbik edilirken kullandığı daha detaylı bir bilgi sisteminin birer parçası olarak görülmelidir (Toluk-Uçar, 2010; Verschaffel, Janssens \& Janssen, 2005).

Alan bilgisi, matematikteki anahtar bilgi, ilke ve kurallarda ustalık, problem çözme teknik ve stratejilerini içerir. Bu bilgi türünde kritik olan öğretmenin matematiği anlama düzeyidir (Ball, 1990; Ma, 1999; Toluk-Uçar, 2010).

Ball’a göre, öğretmenlerin sahip olduğu kavram ve işlem bilgisi doğru olmal1; öğretmenler bunların altında yatan anlam ve ilkeleri anlamalı ve matematiksel düşünceler arasındaki alakaları hem anlamalı hem de takdir etmelidir (Ball, 1990; Toluk-Uçar, 2010).

Eğer öğretmenin matematik bilgisi işlemsel düzeyde ise genellikle açıklamaları da buna benzer olarak işlemsel düzeyde olmaktadır. Ayrıca, öğretmen matematiğin anlamsız kurallar bütünü olduğunu düşünüyorsa, öğrencilerinden bu kuralları anlamadan ezberlemelerini beklemektedir.

Üniversitede alınan eğitim, öğretmen yeterliğine etki eden mühim aşamalarından biridir. Nitekim yapılan çalışmalarda öğretmenler, bu sürecin öğretmeninin yeterliği üzerinde etkili olduğu yönünde görüş ifade etmişlerdir.

Türkiye'de Cumhuriyetin başından itibaren ilkokul öğretmeni yetiştirmeye önem verilmiştir. İlk öğretmen okullarının eğitim süresi 1924'te ilkokuldan sonra dört yıldan beş yıla, 1932-33 öğretim yılında öğretim süresi altı yıla çıkarılmıştır. Bu okulların eğitim süresi 19701971 öğretim yılında yedi yıla, 1974-1975 öğretim yılında liseden sonra iki yıla çıkarılmış ve 
1989-1990 öğretim y1lından itibaren liselerden sonra dört yıllık lisans eğitimi olmak üzere toplam 15 yılı dolduran, günümüzdeki eğitim sistemine başlanmıştır (Şahin, 1998).

Ayrıca öğretmen yetiştirme konusunda çoğu zaman eğitimcilerimiz tarafından gündeme getirilen hususlardan biri, öğretmenlerin uygulamaya dönük olmayan sade bilgiye yönelik dersler almasının yanında, uygulama ve sosyal beceri kazandıran derslerin yetersiz olduğunu ifade etmeleridir (Tan, 1989).

Y1llarca görev yapan öğretmenler, iyi matematik öğretimini gerçekleştirilebilmesi için daha fazla ve gerçekçi bilgiye sahiptirler. Çünkü tecrübeli öğretmen, bilgiyi daha güzel organize eder, kişisel farklılıkları dikkate alır, öğrencilerle daha etkin iletişim kurar ve öğrencilerin ön bilgilerini ve varsa kavram yanılgılarını dikkate alarak daha etkin bir öğretim ve daha etkin ölçme ve değerlendirme yapar (Gürbüz, Erdem ve Gülburnu, 2013).

Öğretmenleri sadece hizmet öncesinde yetiştirip, bu bilgilerle meslek yaşamlarını devam ettirmelerini beklemek, mesleğin gerilemesine ve dolayısıyla eğitimde kalitenin düşmesine neden olacağından öğretmenlerin sürekli kendilerini yetiştirip geliştirmeleri şarttır. $\mathrm{Bu}$ geliştirme de hizmet içi eğitimle olur (Kaçan, 2004).

Öğretmen yeterliklerinde bir kısım özellikler:

Alanında ve alan öğretiminde geniş bilgi, beceri ile kültüre sahip, mesleğiyle ilgili yeni bilgi ve gelişmeleri araştırarak hemen uygulamalarına yansıtan, aydın ve görüşlerinde açık fikirli, farklı kaynaklardan gelen verileri değerlendirerek mesleki uygulamalarında düzenlemeler yapan, eğitimde ve öğretimde liderlik özelliği taşıyan, kişisel gelişimini önemli tutan, 21. yüzyıl kabiliyetlerine sahip, eğitim öğretim sürecini düzenli değerlendirerek sahip olduğu sonuçlara göre uygulamalarını gözden geçiren, yeni mesleki amaçlar belirleyip plan yapabilen, bu süreçte edindiği kazanımları uygulamalarına tatbik eden, öğrencilerinin geleceği görmelerini sağlatarak hayata hazırlayan ve öğrencilerin bireysel farklılıklarına duyarlı olabilen, ahlaklı, terbiyeli, zarif, mesleğini, çocukları/gençleri seven, bulunduğu çevrede ve okulunda fark oluşturan, iletişime değer veren, mesleki tecrübelerini paylaşan, araştırmalarında iş birliğini önemli gören (Özkan, 2016).

Öğretmen yeterliğini etkileyen nedenlerden biri de öğretmenin matematiğge karş1 tutumudur. Tutum doğuştan gelen bir kavram değil, yaşantı yoluyla oluşan bir kavramdır. Bu kavram, bireyin bir durum, olay ya da nesneyle ilgili olumlu ya da olumsuz duyguları olarak ifade edilmektedir (Gürbüz, Erdem ve Gülburnu, 2013; Petty \& Cacioppo, 1996). 
Öğretmen öz-yeterlik inanc1, öğretmenlerin öğrencilerin performanslarını etkileme kapasitelerine veya görevlerini başarılı bir şekilde yerine getirebilmek için gerekli davranışları gösterebilecekleri hususunda inançları olarak ifade edilmektedir (Aston, 1984 akt. Ekici, 2006).

Öz-yeterlik inanc1, öğretmenlerin öğretimi etkili ve verimli bir şekilde yapabileceklerine ve öğrencilerin başarısını artırabileceklerine yönelik kendi yetenekleri hakkındaki yargılarıdır (Akbaş ve Çelikkaleli, 2006).

Eğitim fakültelerinde öğretmen adayları eğitim süreci boyunca birçok ders almaktadır. $\mathrm{Bu}$ derslerden biri de matematik öğretimidir. Öğretmen adaylarının matematik alanında kendilerine yönelik algıları önemlidir. $\mathrm{Bu}$ algılar sonucunda matematiği sevecekler ve matematiğe karşı olumlu tutum oluşturmalarını sağlayacaktır. Buna bağlı olarak öğretmen adayları matematiği öğrenmede ve öğretmede öz-yeterlilik inançları önem kazanacaktır (Aksu, 2008).

Günümüzde İyi bir matematik eğitimi için bilgisayar teknolojisinin doğru kullanımı göz ardı edilemez fakat bilgisayar teknolojisinin sağladıklarıyla bilginin doğrudan aktarılması yerine öğrencinin araştırma yapabileceği ve kendi bilgisini inşa edebileceği ortamların oluşturulması matematik eğitiminde mühim değişiklikleri de beraberinde getirmiştir (Baki, 2006). Bu değişikliklerle birlikte öğretmenin sınıftaki sorumluluğu daha da artmıştır. Öğretmenin öğrenme ve öğretme sürecinde etkin bir şekilde kullanabilmesi için teknolojiyi iyi tanıması gerekmektedir (Demir ve Özmantar, 2013; İlhan ve Aslaner, 2017).

\section{Yöntem}

\section{Araştırma Modeli}

Araştırma nitel bir yaklaşımla yapılandırılmıştır. Bu çalışma kapsamında nitel araştırma türlerinden betimsel analiz kullanılmıştır. Betimsel araştırmalarda sadece var olan durumun ortaya konması amaçlanmıştır.

\section{Evren ve Örneklem}

Yurt dişında ve yurt içinde matematik öğretiminde öğretmen yeterliliklerinin araştırılması konulu çeşitli tarihlerde yayınlanmış hakemli dergilerdeki makaleler, kitaplar ve tezler araştırmanın evrenini oluşturmaktadır. $\mathrm{Bu}$ araştırmalardan, çalışmanın konusuna en uygun olanlar araştırma örneklemini belirlemiştir. Araştırmacının mesleği doğrultusunda yaptığ1 gözlemler ve tecrübesiyle araştırma zenginleştirilmiştir. Böylece öğretmen yeterlilik alanlarını incelemek, öğretmenlerin mesleki gelişimlerine katkıda bulunmak, dolayısıyla 
öğrencilerin matematik başarısına pozitif etkide bulunmak, farkındalık oluşturmak amaçlanmıştır.

\section{Bulgular}

Araştırma kapsamında incelenen çalışmalar, alan ve pedegojik bilgisi, üniversitede alınan eğitim ve öğretmen yetiştirme politikaları, öğretmen deneyimi ve hizmet içi eğitim, öğretmenin tutumu ve öz-yeterlilik inancı gibi ana başlıklar altında analiz edilmiş ve elde edilen bilgiler aşağıda sunulmuştur.

\section{Alan ve Pedegojik Bilgisi}

Pedagojik içerik bilgisi ya da alana özgü pedagoji bilgisi alan bilgisine bağlıdır (McDiarmid, Ball \& Anderson, 1989; Toluk-Uçar, 2010) ve matematiği başkalarının daha iyi anlayabileceği duruma dönüştürmenin yol ve temsil bilgisinden ve öğrencilerin kavram yanılgıları, ön kavramaları ve anlamaları bilgisinden meydana gelir. Bir başka ifadeyle, bu bilgi türü matematiksel kavramların en kullanışılı temsil şekillerinin ne olduğu; matematiksel durumlara en güçlü analoji, örnek ve açıklamaları verebilmeyi; matematiksel kavramların öğrenciler için güçlük seviyesinin ne olduğu, öğrencilerin matematiksel kavramlarla alakalı sezgisel bilgi ve kavram yanılgıları bilgisini ihtiva eder.

Shulman'a göre alan bilgisi, öğretmenin alanındaki kavram ve olguların bilgisini; pedagojik alan bilgisi ise bir konuyu diğerlerine anlaşılır hale getiren gösterim ve formüle etme yollarını ihtiva etmektedir. Bundan dolayı, etkili bir matematik öğretimi için öğretmenin yeterli alan bilgisine sahip olması ve sahip olduğu bu bilgiyi öğrencilere etkin bir şekilde aktarabilmesi gereklidir. Nitekim öğretmenin alan bilgisinin ve pedagojik alan bilgisinin etkili öğretim gerçekleştirebilmek için mühim olduğunu vurguluyan birçok araştırma vardır (Ball, 1988; 1990; Cankoy, 2010; Davis \& Simmt, 2006; Gürbüz, Erdem ve Gülburnu, 2013; Hill, Rowan \& Ball, 2005; Shulman, 1986; 1987; Tchoshanov, 2011).

Matematiğe özgü pedagoji bilgisinin en mühim aşamalarından biri matematiksel kural ve kavramlar için iyi bir öğretimsel açıklama yapabilmektir. Yapılan çalışmalar öğretmenlerin ve öğretmen adaylarının kullandıkları öğretimsel açıklamaların genellikle anlamadan çok ezbere dayalı olduğunu ve dolayısıyla kural ve işlem odaklı olduğunu göstermektedir (Henningsen \& Stein, 1997; Kinach, 2002; Kılcan, 2006; Toluk-Uçar, 2010). Öğretmenlerin öğretimsel açıklamalarının kural ve işlem odaklı olmasının birçok sebebi olabilir. Bu 
sebeplerden bazıları öğretmenlerin matematik bilgilerinin yetersizliği ve matematiğe yönelik tutumlarıdır (Borko \& Putnam, 1996; Prawat, 1992; Richardson, 1996; Thompson, 1992; Toluk-Uçar, 2010).

Gürbüz, Erdem ve Gülburnu (2013)'nun yaptı̆̆g çalışmada öğretmenin sahip olduğu alan bilgisinin ve pedagojik alan bilgisinin matematik öğretiminde çok mühim olduğu ortaya konulmuştur. Bundan dolayı bu iki bilginin beraber kullanılmasının etkili öğretimler ortaya koymak açısından mühim olduğu ortaya konulmuştur.

Konuyla alakalı bir başka araştırmada ise öğretmen adaylarının çoğunun öğretimsel açıklamalarının işlemsel düzeyde kaldığı ifade edilmiştir (Toluk-Uçar, 2010).

Tablo 1. Öğretimsel açıklamaların 4 anlama düzeyine dağılımı

\begin{tabular}{lcc}
\hline & $\mathbf{N}$ & $\mathbf{\%}$ \\
\hline İşlemsel düzey anlama & 161 & 79 \\
\hline Kavram düzey anlama & 27 & 13 \\
\hline Problem çözme düzey anlama & 12 & 6 \\
\hline Epistemik düzey anlama & 4 & 2 \\
\hline
\end{tabular}

Tablo 1 incelendiğinde öğretmen adaylarının matematiksel bilgilerinin genelde işlemsel düzeyde olduğu görülmektedir. $\mathrm{Bu}$ anlama düzeyindeki öğretmen adaylarının öğretimsel açıklamaları ya kuralın nasıl uygulanacağının adım adım anlatılması ya da öğrencinin daha kolay hatırlamasını sağlayacak fakat hiçbir matematiksel temeli bulunmayan "hile" olarak görülecek beyanatlar şeklinde olmuştur. Açıklamaların sadece \% 21 'i kavramsal anlama düzeyinde olmuştur. Fakat kavramsal anlama altında gruplandırılan açıklamaların da yaklaşık üçte ikisi kavram düzeyindedir. Kavram düzeyinde açılklama yapan öğretmen adayları söz konusu işlemlerin ya da kavramların anlamlarını modellemeye çalışmışlardır. Fakat, öğretmen adayları söz konusu kavramların anlamlarını yeterince anlamadıkları için vermiş oldukları açıklamalar ya öğrenci seviyesinin çok üstünde ya da kavramsal açıdan yetersiz kalmıştır. Örneğin, kesirlerle toplama ve çıkarma sorularında öğretmen adayları payda eşitlemenin gerekliliğini ifade etmeye çalışırken yaptıkları açıklamalarda söz konusu kesirlerin birimlerinin büyüklüğünün aynı olmadığını hissettirmeye çalışmışlardır. Fakat bunu açıklarken yine payda eşitlemenin işlemsel yönünü ön plana çıkarmışlardır. Aslında payda eşitlemenin, işlemdeki sayıları ortak bir birim kesir türünden yani bu kesirlere denk kesirler oluşturma olduğunu anlayamamışlardır. Sonuç olarak, payda eşitlerken pay ve paydanın aynı sayı ile çarpıımasının aslında söz konusu miktarın çarpılan sayı kadar yeniden eş parçaya bölündüğünü anlamadıkları 
görülmüştür. Bunun aksine öğretmen adayları çarpılan sayı kadar miktarların büyüdüğünü ifade etmişlerdir (Toluk-Uçar, 2010).

Toluk-Uçar (2010)'ın yaptığı çalışmada görüldüğü gibi öğretmen adayları söz konusu işlemleri yeterince anlamadıkları sadece işlemsel düzeyde bildikleri için öğrenciye bu bilgiyi işlemsel düzeyde verebileceklerini belirtmektedirler. Ayrıca, öğretmen adayları açıklama verememelerine sebep olarak kendilerinin de bu kavramları ve işlemleri işlemsel düzeyde öğrenmiş olmalarını ifade etmişlerdir. Bu açıklamalardan çıkarılabilecek mühim bir sonuç ise bazı öğretmen adaylarının kuralların öğretimsel açıklama olarak kullanılmasının anlamayı desteklemeyeceğinin farkında olmalarıdır.

Yine Toluk-Uçar (2010)'ın yaptığı çalışmada öğretmen adaylarının izah etmekte zorlandıkları durumlarda bazı hilelere müracaat ettikleri görülmüştür. Özellikle kesirlerle işlemlerde öğretmen adayları uygun açıklama verebilecek düzeyde matematiksel anlamaya sahip olmadıkları durumlarda bu kaçış yollarına müracaat etmişlerdir. Bu tür açıklamalarda öğretmen adayları kurallara ya da kavramlara şeklen yaklaşmış, bu tür açıklamalar matematiksel kural ve kavramların anlamsız sembollerle yapılan bir oyun olduğu düşüncesini yansıtmıştır. Bu tür hileli açıklamalarda, öğretmen adayı hiçbir şekilde matematiksel bir gerekçe sunmamıştır.

Gürbüz, Erdem ve Gülburnu (2013)'nun yaptığı çalışmada, üniversitede alınan eğitim, öğretmen yeterliğine etki eden mühim süreçlerden biri olduğu belirtilmiştir. Nitekim araştırmaya katılan öğretmenler, bu sürecin sınıf öğretmeninin matematik yeterliği üzerinde etkili olduğunu ifade etmişlerdir.

\section{Üniversitede Alınan Eğitim ve Öğretmen Yetiştirme Politikaları}

Gürbüz, Erdem ve Gülburnu (2013)'nun yaptığg çalışmada, üniversitede alınan eğitim, öğretmen yeterliğine etki eden mühim süreçlerden biri olduğu sonucuna varılmıştır.

Öğretmenler, üniversitede verilen eğitimin öğretmenin matematik yeterliği üzerinde etkili olduğu yönünde görüş bildirmişlerdir. Öğretmenlerin bu konuşmalarından sınıf öğretmenlerinin matematik yeterliklerinde üniversitede verilen matematik eğitiminin mühim rol oynadığı anlaşılmıştır. Nitekim, öğretmenin matematik yeterliğinde üniversitelerde verilen eğitimin önemini ifade eden birçok araştırma mevcuttur (Hill Vd., 2005; Küçük vd., 2010; Peker, 2009; Smith, 2000; Ubuz, 2002; akt. Gürbüz, Erdem ve Gülburnu, 2013).

Öğretmen yetiştiren okulların üniversiteye devredilmesinden sonra meslek derslerinin sabit kaldığ 1 ve alan bilgisi derslerinin artması sonucunda, bu derslerin oran $1 \% 20-25$ ’lerden \%10-12'lere kadar düştüğü kaydedilirken, 1998'den itibaren eğitim fakültelerinin yeniden 
yapılandırılması sonucunda okul deneyimi ve öğretmenlik uygulamalarına ayrılan sürenin ilköğretim bölümlerinde yaklaşık üç kat artırılmasının nitelik bakımından öğretmenlik mesleğine mühim katkı sağlayacağı kaydedilmiştir (Öztürk, 2001).

\section{Öğretmen Deneyimi ve Hizmet İçi Eğitim}

Bilgi ve anlayışlar sürekli gelişerek tecrübe kavramını oluşturmaktadırlar. Öğretmenlik mesleğinin etkili yürütülmesinde de tecrübe kavramı ön plana çıkmaktadır. Çünkü tecrübeli öğretmen, bilgiyi daha güzel organize eder, kişisel farklılıkları dikkate alır, öğrencilerle daha etkili iletişimler kurar ve onların ön bilgilerini ve varsa kavram yanılgılarını göz önüne alarak daha etkili bir öğretim ve daha etkili ölçme ve değerlendirme yapar. Bu bağlamda, araştırma sürecine katılan bazı öğretmenlerin, öğretim sürecinin etkin yürütülmesinde mesleki deneyimin önemine ilişkin görüşler belirtmişlerdir (Gürbüz, Erdem ve Gülburnu, 2013).

Araştırmaya katılan öğretmenlerin geneli mesleki deneyimin öğretmen yeterliğini olumlu etkilediğini ve öğrenci başarısını arttırdığını dile getirmişlerdir. Fakat bazı öğretmenler deneyim arttıkça öğretmenin her açıdan yeterliğinin arttığını ifade ederken, bazıları özellikle meslek hayatlarının sonlarına yaklaşmış öğretmenlerin derslerini hala geleneksel yöntemle işlediklerini ifade etmişlerdir. Burada mesleki deneyim kavramıyla çalışma yılı kavramının birbirinden ayrılması gerekmektedir. Mesleki deneyim, meslek hayatında edinilen bilgilerin ya da karşılaşılan durumların yeni bilgi ve gelişmelerle yoğrulmasıyla elde edilir ve gelişir. $\mathrm{Bu}$ noktada, diğer mesleklerde olduğu gibi öğretmenlik mesleğinde yıllarca çalışmış her öğretmenin deneyimli olduğu söylenemez. Yukarıda açıklanan şekliyle mesleki deneyimin, öğretmenlerin yeterliğini etkileyen mühim bir faktör olduğu söylenebilir.

Öğretmenin mesleğine girdikten sonra yapılan, bireysel gelişme, ilerleme ve eğitim sisteminin ihtiyaçlarını karşılamayı hedefleyen (Barros, 1995; Kaçan, 2004) hizmet içi eğitim, öğretmenlerin mesleki yeteneklerini korumaları, değişen rollerini yerine getirebilmeleri için gerekli olan bir eğitimdir. Veenman'ın belirttiği gibi öğretmenler açısından hizmet içi eğitimin yararları şunlardır (Kaçan, 2004; Silvester, 1997):

- Öğretmenlerin bilimsel, eğitsel ve kişisel yeteneklerini arttırarak, profesyonel gelişimini teşvik etme,

- Okul gelişimini ve uygulamalarını geliştirme,

- Okullarda politik onay almış gelişimleri tamamlama,

- Öğretmenleri mesleki doyuma yöneltme, 
Öğretmenlerin mesleki hayatlarını devamlı güncel tutmak, onları çağdaş yöntemlerden, araştırma sonuçlarından ve eğitimdeki diğer gelişmelerden haberdar etmek, sürekli değişen ve çoğalan durumlara hazırlamak hizmet içi eğitimle mümkün olmaktadır (Özyürek, 1981).

\section{Öğretmenin Tutumu}

Gürbüz, Erdem ve Gülburnu (2013)'nun yaptı̆̆ çalışmada, öğretmenlerin matematiğe ilişkin sahip oldukları olumlu ya da olumsuz tutum, öğrencileri zihinsel ve duyuşsal yönden etkileyebilmektedir. Bu bağlamda, matematiğe yönelik olumlu ya da olumsuz tutumun öğretim sürecini etkilediğine ilişkin bazı öğretmen görüşlerine saptanmıştır.

Sınıf öğretmenlerinin matematikle alakalı tutumlarının ve matematik geçmişlerinin, onların yeterliği ve yetiştirdikleri öğrencilerin matematik başarıları üzerinde etkili olduğu söylenebilir. Öğretmenlerin matematikle alakalı bu tutumları öğrencilerin başarılarını da direkt etkilemektedir. Nitekim öğretmenin matematikle alakalı tutumunun öğrencilerin öğrenmelerine yansıdığını belirten araştırmalara rastlamak mümkündür (Aiken, 1976; Brown \& Baird, 1993; Bulmahn \& Young, 1982; Gürbüz, Erdem ve Gülburnu, 2013; Kelly \& Tomhave, 1985; Larson, 1983; Wood, 1988).

\section{Öz-Yeterlilik İnancı}

Alanında yetkin olmayan bir öğretmenin öğrencilerine güven vermesi ve sınıfta saygıya dayalı bir otorite oluşturması beklenmez. Öz-yeterlik, bireyin kendisine ilişkin algısı olduğuna göre, iyi yetişmiş matematik öğretmen adaylarının her şeyden önce matematiğe ilişkin özyeterlik algılarının yüksek olması beklenir (Umay, 2002).

Öğretmenlerin öğretimle ilgili öz yeterlik inançları ile başarısı arasında bir pozitif alaka olduğu ve öz-yeterliliği güçlü olan öğretmenlerin öğrencilerini daha başarılı yapacak yöntemleri deneme arzularının arttığı, daha istekli ve üst düzey performans başarıları gösterdikleri görülmektedir (Korkmaz vd., 2004). Ayrıca, öğretmen öz-yeterliği sınıf içi davranışları değiştirmede, yeni fikirlere açık olmada ve öğretmeye yönelik olumlu tutumlar geliştirmeyle de direkt alakalı olabilmektedir (Hamurcu, 2006).

Aksu (2008)’nun öğretmen adaylarının matematiğe yönelik öz-yeterlik inançlarını tespit etmek için yaptığı çalışmada 232 öğretmen adayının görüşü alınmış ve anketten aldıkları puan dağılımı incelenmiştir. Öğretmen adaylarının Öz-yeterlik inancı, Başa çıkma davranışı alt boyutunda ve genel puanların dağılımı tablo 2'te verilmektedir.

Tablo 2. Öz-yeterlik inancı ve başa çıkma davranışına ait puanların dağılımı

\begin{tabular}{llcccc}
\hline Boyut & $\mathrm{N}$ & En düşük puan & En yüksek puan & $\mathbf{X}$ & SS \\
\hline Öz-yeterlik inanc1 & 232 & 14 & 70 & 53.67 & 6.89 \\
\hline
\end{tabular}




\begin{tabular}{lccccc}
\hline Başa çıkma davranışı & 232 & 10 & 50 & 35.83 & 4.5 \\
\hline Toplam & 232 & 24 & 120 & 89.50 & 10.16 \\
\hline
\end{tabular}

Öğretmen adaylarının matematik öğretimine ilişkin öz-yeterlilik inançlarının belirlemesi amacıyla hazırlanan ölçeğin öz-yeterlik alt boyutunda maddelerin tamamı karasızım işaretlenmiş olsa toplam 42 puan, Başa çıkma davranışı alt boyutunda maddelerin tamamı kararsızım işaretlenmiş olsa toplam 30 puan ve genel toplamda aynı işlem yapılsa toplam 72 puan alabilmektedir. Tablo 2'de aritmetik ortalamaları bu puanlarından yüksek olduğu açıkça görülmektedir. Bu da öğretmen adaylarının olumlu yönde öz-yeterlik inançlarının ölçekten alınabilecek toplam puan ortalamasının üzerinde olduğunu ifade etmektedir. Aritmetik ortalamanın yüksek puana yakın değerde olması öğretmen adaylarının matematiğe yönelik özyeterlik inançlarını lisans eğitimi boyunca geliştirdiği ve 4 . Sınıf sonunda dikkate değer bir seviyeye geldiği sonucuna varılabilir.

\section{Tartışma, Sonuç ve Öneriler}

İyi düzeyde bir alan bilgisine sahip olup, bu bilgiyi öğrencilere nasıl aktaracağını bilemeyen bir öğretmenin de iyi bir öğretim gerçekleştiremeyeceği söylenebilir. Nitekim tüm katılımcılar, etkili bir matematik öğretimi için öğretmenin alan bilgisinin yeterli düzeyde olmasının yanı sıra bu bilgiyi öğrenenlerine iyi aktarabilmesinin de çok mühim olduğu konusunda fikir birliğine varmışlardır (Gürbüz, Erdem ve Gülburnu, 2013).

Öğretmen adaylarının yapmış olduğu açıklamaların büyük bir çoğunluğu işlemlerin kurallarının tekrarı şeklinde olmuştur. Öğretmen adayları açıklamalarında kuralların nasıl uygulanacağının anlatılmasının yanı sıra hiçbir matematiksel dayanağı olmayan ifadelere de yer verdikleri görülmüştür. Çok az öğretmen adayı kavramsal düzeyde açıklama yapabilirken hemen hemen hiç biri işlemlerin kurallarının altında yatan anlamları ve sebepleri ifadelerinde kullanmamıştır. Ayrıca, öğretmen adaylarının algoritma ve kural bilgisinin iyi olduğu görülmüştür. Fakat sıfır sayısı ile ilgili bazı kavram yanılgılarına sahip oldukları gözlenmiştir. Bazı öğretmen adayları sıfırın bir sayı olmadığını bir sembol olduğunu ifade etmişlerdir (TolukUçar, 2010).

İlköğretim matematik öğretmen adaylarının matematik okuryazarlı̆̆ı öz yeterlik inançlarının cinsiyete göre anlamlı farklılık gösterdiği ifade edilmiş ve kız öğretmen adaylarının öz-yeterlik inançları erkeklere göre daha düşük olduğu görülmüştür (Zehir ve Zekir, 2016). Özgen ve Bindak (2011)'ın yaptığı araştırmada lise öğrencilerinin matematik okuryazarlığı öz yeterlilik inançlarının cinsiyete göre anlamlı farklılık gösterdiği görülmüş ve kız öğrencilerin 
öz-yeterlik inançları erkeklere göre daha olumsuz olduğu görülmüştür. Benzer şekilde Hackett ve Betz (1989), Pajares ve Miller (1994), Schnulz (2005) ve Özyürek (2010) tarafindan yapılan çalışmalarda da matematik okur yazarlığı öz-yeterlik ve cinsiyetle alakalı olduğu ve kızlarda daha düşük olduğunu ortaya koyan çalışma bulguları ortaya konulmuştur (Zehir ve Zekir, 2016).

Katılımcılar, üniversitede verilen eğitimin öğretmenin matematik yeterliği üzerinde etkili olduğu yönünde görüş beyan etmişlerdir. Bu yönde görüş beyan eden öğretmenler, üniversitede verilen matematik eğitimiyle meslek hayatlarında gerçekleştirdikleri matematik eğitiminin birbirinden çok farklı olduğunu ve üniversitede daha çok teorik ağırlıklı bir matematik eğitimi aldıklarını ifade etmişlerdir. Bu uyuşmazlığın önüne geçmek için ise öğretmen adaylarının üniversite yıllarında gerçek sınıf ortamlarında daha fazla öğretimler gerçekleştirmesi gerektiği ortaya çıkmıştır (Gürbüz, Erdem ve Gülburnu, 2013).

Öğretmenin mesleki tecrübesi, matematik yeterliğini etkileyen diğer bir faktör olarak görülmüştür. Katılımcıların geneli mesleki tecrübenin öğretmen yeterliğini olumlu etkilediğini ve öğrenci başarısını arttırdığını ifade etmişlerdir. Mesleki tecrübe, meslek hayatında edinilen bilgilerin ya da karşılaşılan durumların yeni bilgi ve gelişmelerle yoğrulmasıyla elde edilir ve gelişir. Fakat bazı öğretmenler tecrübe arttıkça öğretmenin her açıdan yeterliğginin arttığını ifade ederken, bazıları özellikle meslek hayatlarının sonlarına yaklaşmış öğretmenlerin derslerini hala geleneksel yöntemlerle işlediklerini beyan etmişlerdir. Bu noktadan hareketle, mesleki tecrübe kavramıyla çalışma yılı kavramlarının farklı kavramlar olduğu anlaşılmalıdır. Başka bir ifadeyle, öğretmenlik mesleğinde yıllarca çalışmış her öğretmenin tecrübeli olduğu söylenemez (Gürbüz, Erdem ve Gülburnu, 2013).

Öğretmenlerin matematiğe ilişkin sahip oldukları olumlu ya da olumsuz tutum, öğrencileri hem zihinsel hem de duyuşsal yönden etkileyebilmektedir. Matematik geçmişinde ve halen matematikle alakalı olumlu tutuma sahip olan öğretmenlerin meslek hayatlarında da başarılı oldukları ifade edilebilir. Nitekim katılımcılar, öğretmenlerin matematikle alakalı tutumlarının ve matematik geçmişlerinin, onların yeterliği ve yetiştirdikleri öğrencilerin matematik başarıları üzerinde etkili olduğunu beyan etmişlerdir (Gürbüz, Erdem ve Gülburnu, 2013).

Deringöl (2018)’ün yaptığı çalışmamaya göre sınıf öğretmeni adaylarının matematik öğretimi kaygılarının az oldukları söylenebilir. Öğretmen adaylarının matematik öğretimi kaygılarının yüksek olmaması öğretmenlerim matematik öğretimi yeterliklerini daha rahat bir şekilde ortaya koyacakları düşüncesini akla getirebilir. Birçok çalışmada da öğretmen 
adaylarının matematik öğretimi kaygılarının çok olmadığ 1 sonucuna ulaşılmıştır (Bekdemir, 2007; Elmas, 2010; Hacıömeroğlu; 2014; Peker, 2008; Tatar, Zengin, ve Kağızmanlı, 2016; Ural, 2015).

Yenilmez (2017)'in yaptığı araştırmaya göre ilköğretim matematik ve sınıf öğretmeni adaylarının matematik öğretimine yönelik öz-yeterliklerinin, okul öncesi öğretmeni adaylarına göre daha düşük olmadığı ortaya konulmuştur. Ayrıca yine bu araştırma da akademik başarısı yüksek olan öğretmen adaylarının akademik öz-yeterliklerinin ve matematik öğretimine yönelik öz-yeterliklerinin daha yüksek olduğu sonucuna varılmıştır.

Öğretmenlerin başarılı bir eğitim-öğretim süreci yaşayabilmeleri kendi öz-yeterlik inançlarına bağlıdır. Öğretmen öz-yeterlik inancı konusunda yapılan araştırmalar incelendiğinde, öz-yeterlik inancı yüksek olan öğretmenlerin, daha planlı, düzenli ve bilinçli oldukları, öğrencilerin gereksinimlerini karşılamaya yönelik yeni yaklaşımlar aramaya istekli oldukları, sınıf yönetiminde olumlu yaklaşımlar kullandıkları, öğrenci başarısını ve motivasyonunu yüksek tutabilmekte daha başarılı oldukları ifade edilmektedir (Akbaş ve Çelikkaleli, 2006; Aksu, 2008; Ekici, 2006; Günhan ve Başer, 2007; Hamurcu, 2006; Umay, 2002).

- Üniversite yıllarında öğretmen adayının yeterli düzeyde alan bilgisi ve pedagojik alan bilgisine sahip olması sağlanmalıdır.(Gürbüz, Erdem ve Gülburnu, 2013)

- İlkokulda matematik dersi için branş öğretmenleri yetiştirilebilir.

- Öğretmenlerin yüksek lisans veya doktora mezunu olmaları için imkanlar artırılabilir, bu programlardan mezun olanları MEB'te çalışmaya devam ettirmek için teşvikler verilebilir.

- Öğretmenlerin matematik yeterliklerini geliştirmeleri için yeterli seviyede ve kalitede hizmet içi eğitim seminerleri düzenlenebilir.

- Öğretmen adaylarının hizmet öncesi eğitimlerinde, liseden getirdikleri matematik bilgilerini kavramsal şekle dönüştürebilmeleri için lisans programlarındaki dersler yeterli değildir. $\mathrm{Bu}$ derslerin içeriklerinin yeniden düzenlenmesi ve haftalık ders saatinin artırılması gerekmektedir.

- Öğretmenlerin maddi sorunları çözülebilir, ders yükleri ve sınıf mevcutları azalt1labilir.

- Öğretmen adaylarının matematik öğretimine yönelik öz-yeterlik inançlarını etkileyen etkenler incelenebilir (Aksu, 2008). Bu bağlamda hizmet içi eğitim programları düzenlenebilir. 
- Okullarda öğretmenlerin her an yararlanabilecekleri eğitim danışmanları (eğitim planlaması, program geliştirme uzmanı, okul danışmanı, özel eğitim uzmanı, eğitim teknolojisi uzmanı, ölçme ve değerlendirme uzmanı, rehberlik uzmanı) görevlendirilmelidir (Kaçan, 2004).

- Eğitim fakülteleri ile iş birliği yapılabilir.

- Öğretmen adaylarının okullarda yaptıkları stajlar arttırılabilir ve daha kaliteli hale getirilebilir. Hatta tıp fakültelerinde uygulama hastaneleri olduğu gibi eğitim fakültelerinin de uygulama okulları oluşturulabilir.

- Sınıf öğretmenlerinin matematik yeterliklerinde matematik branş öğretmenleriyle işbirliği yapabilir.

\section{Makalenin Bilimdeki Konumu}

Eğitim Bilimleri/Eğitim Programları ve Öğretim Anabilim Dalı

\section{Makalenin Bilimdeki Özgünlüğü}

Yapılan bu araştırma, öğrencilerin matematik başarısının etkenlerinden biri olan öğretmen yeterliliklerini inceleyip, bir durum betimlemesi yapmaktadır. Öğretmenlerin mesleki başarılarını arttırmaya katkıda bulunmakta veya yaşadıkları öğretimsel sorunları çözmek için fikir beyan etmektedir. Genel olarak matematik dersi için var olan sorunlar irdelenmiş ve çözüm önerileri sunulmuştur. Öğretimi etkileyen tüm faktörler ele alınamamış fakat belli başlı faktörler irdelenmiştir. Öğretmen yeterliliklerinin bir kısmı incelenmiştir.

\section{Kaynaklar}

Aiken, L. R. (1976). Update on attitudes and other affective variables in learning mathematics. Review of Educational Research, 46, 293-311.

Akbaş, A. ve Çelikkaleli, Ö. (2006). Sınıf öğretmen adaylarının fen öğretimi öz-yeterlik inançlarının cinsiyet, öğretnim türü ve üniversitelere göre incelenmesi. Mersin Ĕ̆itim Fakültesi Dergisi, 2, 98-110.

Aksu, H. H. (2008). Öğretmen adaylarının matematik öğretimine yönelik öz-yeterlilik inançları. Abant İzzet Baysal Üniversitesi Ĕgitim Fakültesi Dergisi, 8(2).

Ataünal, A. (2000). Öğretmenlik Mesleğine Giriş veya Nasıl Bir Insan? Ankara: 20 Mayıs Eğitim Kültür ve Sosyal Dayanışma Vakfı Yayınları.

Baki, A. (2006). Kuramdan uygulamaya matematik ĕgitimi. Trabzon: Derya Kitabevi. 
Ball, D. L. (1988). Knowledge andreasoning in mathematical pedagogy: Examining what prospective teachers bring to teacher education. Yayınlanmamış Doktora Tezi, Michigan StateUniversity, East Lansing.

Ball, D. L. (1990). The mathematical understandings that prospective teachers bring to teache reducation. Elementary School Journal, 90, 449-466.

Baloğlu, N. (2001). Etkili Sınıf Yönetimi. Ankara: Baran Ofset.

Barros, Joao Pedro De (1995). “Portekiz’deki Öğretmen Eğitim Sistemleri”, Avrupa Konseyi Ülkelerinde Öğretmen Yetiştirme Politika ve Modelleri (21-26 Eylül 1992, İzmir), MEB, Ankara, s.159-167.

Başaran, İ. E. (1994). Eğitime Giriş. Ankara: Kadığlu Matbaası.

Bekdemir, M. (2007). İlköğretim matematik öğretmen adaylarındaki matematik kaygısının nedenleri ve azaltılması için öneriler (Erzincan Eğitim Fakültesi Örneği). Erzincan Eğitim Fakültesi Dergisi, 9(2), 131-144.

Borko, H., \& Putnam, R. (1996). Learning toteach. In D. Berliner, \& R. Calfee (Eds.), Handbook of educational psychology (pp. 673-708). New York: Macmillan.

Brown, C. A,. \& Baird, J. (1993). Inside the teacher: Knowledge, beliefs, and attitudes. In Wilson, P. S. Research Ideas in the Classroom: High School Mathematics. New York: Macmillan.

Bulmahn, B. J., \& Young, D. M. (1982). On the transmission of mathematics anxiety. Arithmetic Teacher, 30 (3), 55-56.

Büyükkaragöz, S. S. ve Çivi, C. (1999). Genel öğretim metotları. 9. Baskı. Konya: Öz Eğitim Yayınları.

Cankoy, O. (2010). Mathematics teachers' topic-specific pedagogical content knowledge in the context of teaching a 0,0 ! and a $\div 0$. Educational Sciences: Theory\&Practice, 10(2), 749-769.

Carpenter, T. P.,Fennema, E., \& Franke, M. L., (1996). Cognitively guided instruction: a knowledge base for reform in mathematics instruction. The Elementary School Journal, 97(1), 3-20.

Çakan, M. (2004). Öğretmenlerin ölçme-değerlendirme uygulamaları ve yeterlik düzeyleri: ilk ve ortaöğretim. Ankara Üniversitesi Eğitim Bilimleri Fakültesi Dergisi, 37(2), 99-114.

Davis, B., \& Simmt, E. (2006). Mathematics-for-teaching: An on going investigation of the mathematics that teachers (needto) know. Educational Studies in Mathematics, 61, 293319. 
Demir, S. ve Bozkurt, A. (2011). İlköğretim matematik öğretmenlerinin teknoloji entegrasyonundaki öğretmen yeterliklerine ilişkin görüşleri. İlköğretim Online, 10(3), 850-860.

Demir, S. ve Özmantar, M.F. (2013). Teknoloji destekli matematik ögrretiminde pedagojik prensipler. Nobel-Atlas Yayıncılık. Ankara.

Deringöl, Y. (2018). Sınıf öğretmeni adaylarının matematik öğretimi kaygıları ve matematik öğretimi yeterliklerinin incelenmesi. Kuramsal Eğitimbilim Dergisi, 11(2), 261-278.

Dursun, Ş. ve Dede, Y. (2004). Öğrencilerin matematikte başarısını etkileyen faktörler:matematik öğretmenlerinin görüşleri bakımından. Gazi Eğitim Fakültesi Dergisi, 24(2), 217-230

Ekici, G. (2006). Meslek Lisesi Öğretmenlerinin Öğretmen Öz-yeterlik inançları Üzerine Bir Araştırma. Eğitim Araştırmaları, 8, 87-96.

Elmas, S. H. (2010). Sınıf ögretmeni adaylarının matematik öğretmeye yönelik kaygı düzeyleri ve bu kayglya neden olan faktörler (Yayınlanmamış yüksek lisans tezi). Afyon Kocatepe Üniversitesi, Sosyal Bilimler Enstitüsü, Afyon.

Fidan, N. ve Erden, M. (1994). Eğitime Giriş. 5. Baskı. Ankara: Meteksan Matbaacılık.

Franke, L. \& Kazemi, E. (2001). Learning to teach mathematics: focus on student thinking. The Oryinto Practice. Spring, 40 (2), 102-109.

Gray, E. \& Tall, D. (1992). Successand failure in mathematics: the flexible meaning of symbols as processand concept. MathematicsTeaching, 142, 6-10.

Günhan-Cantürk, B. ve Başer, N. (2007). Geometriye yönelik öz-yeterlik ölçeğinin geliştirilmesi. Hacettepe Ĕ̌gitim Fakültesi Dergisi, 33, 68-76.

Gürbüz, R., Erdem, E. ve Gülburnu, M. (2013). Sınıf öğretmenlerinin matematik yeterliklerini etkileyen faktörlerin incelenmesi. Ahi Evran Üniversitesi Kırşehir Ĕgitim Fakültesi Dergisi (KEFAD) 14(2), 255-272.

Hacıömeroğlu, G. ve Şahin, Ç. (2011). Sınıf öğretmeni adaylarının uygulama öğretmenleri hakkındaki özel alan yeterlikleri algısı. Mustafa Kemal Üniversitesi Sosyal Bilimler Enstitüsü Dergisi, 8(15), 473-486.

Haciömeroğlu, G. (2014). Elementary pre-service teachers' mathematics anxiety and mathematics teaching anxiety. International Journal for Mathematics Teaching and Learning. http://www.cimt.plymouth.ac.uk/journal/haciomeroglu.pdf adresinden 09.04.2017 tarihinde indirilmiştir. 
Hamurcu, H. (2006). Sınıf Öğretmen Adaylarının Fen Öğretimine Yönelik Öz-yeterlik inançları. Ë̆itim Araştırmaları. 8, 112-122

Hare, M. (1999). Revealing what urban early childhood teachers think about mathematic sand how they teachit:1mplications for practice. University Of North Texas, December, s.11.

Henningsen, M. \& Stein, M. K., (1997). Mathematical tasksand student cognition: Classroombased factors that supportandinhibithigh-level mathematical thinking andreasoning. Journal for Research in Mathematics Education, 28, 524-549.

Hill, H. C., Rowan, B. \& Ball, D. L. (2005). Effects of teachers' mathematical knowledge for teaching on student achievement. American Educational Research Journal, 42(2), 371406.

Hollins, E. R. (2011). Teacher preparation for quality teaching. Journal of Teacher Education, 62(4), 395-407.

İlhan, A. ve Aslaner, R. (2017). Geometri konularının öğretiminde dinamik geometri yazılımı kullanımının ilköğretim matematik öğretmen adaylarının görsel matematik okuryazarlık alg1 düzeylerine etkisinin incelenmesi. NEF-EFMED, 11(2), 136-155.

Kaçan, G. (2004). Sınıf öğretmenlerinin mesleki gelişime ilişkin isteklilik düzeyleri. Osmangazi Üniversitesi Sosyal Bilimler Dergisi, 5(1).

Kelly, W. P. \& Tomhave, W. K. (1985). A study of math anxiety/math avoidance in preservice elementary teachers. Arithmetic Teacher, 32(5), 51-53.

Kılcan, S. (2006). İlköğretim matematik öğretmenlerinin kavramsal bilgileri: Kesirlerle bölme. Yayınlanmamış Yüksek Lisans Tezi, Abant İzzet Baysal Üniversitesi.

Kinach, B. M. (2002). Understanding and learning-to-explain by representing mathematics: Epistemological dilemmasfacing teachereducators in the Secondary mathematics “methods” course. Journal of Mathematics Teacher Education, 5, 153-186.

Korkmaz, E., Gür, H. ve Ersoy, Y. (2004). Problem kurma ve çözme yaklaşımlı matematik öğretimi-II: Öğretmen adaylarının alışkanlıkları ve görüşleri, Matematikçiler Derneğ $i$ Bilim Köşesi, 18 Ekim 2007 tarihinde http://www.matder.org.tr/Default.asp?id=132

Larson, C. N. (1983). Techniques for developing positive attitudes in preservice teachers. Arithmetic Teacher, 31(2), 8-9.

Ma, L. (1999). Knowing and teaching elementary mathematics: Teachers' understanding of fundamentalmathematics in Chinaandthe United States. Mahwah, NJ: Erlbaum. 
McDiarmid, G. W., Ball, D. L. \& Anderson, C. (1989). Why staying one chapter ahead doesn't really work: subject-specificpedagogy. In M. C. Reynolds (Ed.), Knowledge Base for the Beginning Teacher (pp. 193-205). Elmsford, NY: Pergamon Press.

MEB (2018). İlköğretim matematik dersi 6-8. sınıflar öğretim programı. T.C. Milli Eğitim Bakanlığı. Talim ve Terbiye Kurulu Başkanlığı, Ankara.

Meece, J. (1996). Gender differences in mathematics achievement: the role of motivation, In M. Carr (Ed.), Motivation in mathematics. HamptonPress, Inc. Cresskill, New Jersey.

National Council of Teachers of Mathematics (NCTM) (1989). Curriculumand evaluation standardsfor school mathematics, Reston, VA: Author.

National Council of Teachers of Mathematics (NCTM) (2000). Principlesand standards for school mathematics, Reston, VA: Author.

Özkan, İ. (2016). Türk eğitiminde öğretmen okulları ve öğretmen yeterliliklerine dair düşünceler. 21. Yüzyılda Eğitim ve Toplum, 5(15), 19-27.

Öztürk, C. (2001). 21.Yüzyılın eşiğinde Türkiye'de öğretmen yetiştirme, (Ed:O.O_uz, vd.), 21.Yüzyılda Ĕgitim ve Türk Ĕ̌itim Sistemi, Sedar Yay., İstanbul, (223-280).

Özyürek, L. (1981). Öğretmenlere yönelik hizmet içi eğitim programlarının etkinliği, Ankara Üniversitesi Ĕ̆itim Fakültesi Yayınlarl, Ankara.

Peker, M. (2008). Pre-service teachers' teaching anxiety about mathematics and their learning styles. Eurasia Journal of Mathematics, Science \& Technology Education, 5(4), 335345. doi: https://doi.org/10.12973/ejmste/75284

Petty, R. E. \& Cacioppo, J. T. (1996). Attitudes and persuasion: classic and contemporary approaches. Colarado: Westviev Press.

Prawat, R. S. (1992). Teachers' beliefs about teaching and learning: A constructivist perspective. American Journal of Education, 100(3), 354-395.

Richardson, V. (1996). The role of attitudes and beliefs in learning to teach. In J. Sikula (Ed.), Handbook of Research on Teacher Education (pp. 102-119). New York: Macmillan.

Rosenholtz, S. J. (1985). Political myth about education reform: Lessons from research on teaching. Phi Delta Kappan, 66(5), 349-355.

Seferoğlu, S. S. (2001). Sınıf öğretmenlerinin kendi meslekî gelişimleriyle ilgili görüşleri, beklentileri ve önerileri. Milli Ĕgitim Dergisi, 149.

Shulman, L. S. (1986). Those who understand: knowledge growth in teaching. Educational Researcher, 15(2), 4-14. 
Shulman, L. S. (1987). Knowledge and teaching: foundation of thenew reform. Harvard Educational Review, 57(1), 1-22.

Silvester, H. (1997). “Inset, projects and evaluation”, In-service teacher development: International Perspectives, Edtt.David Hayes, Prentice Hall, London, s.109-115.

Smith, M. (2000). Redefinıng success in mathematıcs teaching and learning.

MathematicsTeaching in theMiddle School. February, 5(6).

Stafslien, C. (2001). Gender differences in achievement in mathematics. November16.http://www.math.wisc.edu/ weinberg/MathEd/Gender_Term_Pape

Şahin, M. (1998). İlköğretimde öğretmen yetiştirme süresi. Millî Eğitim, 137, (91-99).

Tan, H. (1989). Türk eğitiminde kalite sorunu. Marmara Ün. Atatürk Eğit. Fak. Eğitim Bilimleri Dergisi, 7, (129-139).

Tatar, E., Zengin, Y. ve Kağızmanlı, T. B. (2016). Öğretmen adaylarının matematik öğretmeye yönelik kaygı düzeylerinin incelenmesi. Kuramsal Ĕ̆itimbilim Dergisi, 9(1), 38-56. http://dx.doi.org/10.5578/keg.10006

Tchoshanov, M. A. (2011). Relationship between teacher knowledge of concept sand connections, teaching practice, and student achievement in middle grades mathematics. Educational Studies in Mathematics, 76, 141-164.

Thompson, A. G. (1992). Teachers' belief sand conceptions: A synthesis of theresearch. In D. A. Grouws (Ed.), Handbook of research on mathematic steachingand learning (pp. 127146). New York: Macmillan.

Toluk-Uçar Z. (2010). Sınıf öğretmeni adaylarının matematiksel bilgileri ve öğretimsel açıklamaları. E-Journal of New World Sciences Academy Education Sciences, 1C0174, 5(3), 911-920.

Umay, A. (2002). İlköğretim matematik öğretmenliği programının öğrencilerin matematiğe karşı öz-yeterlik algısına etkisi. V. Ulusal Fen Bilimleri ve Matematik Ĕgitimi Kongresi. (16-18 Eylül 2002). Ankara: ODTÜ Kültür ve Kongre Merkezi.

Ural, A. (2015). Matematik öz-yeterlik algısının matematik öğretmeye yönelik kaygıya etkisi. Kuramsal Eğitimbilim Dergisi, 8(2), 173-184. doi: http://dx.doi.org/10.5578/keg.9075 Verschaffel, L., Janssens, S. \& Janssen, R. (2005). The development of mathematical competence in Flemishpre-service elementary school teachers. Teaching and Teacher Education, 21, 49-63.

Wood, E. F. (1988). Math anxiety and elementary teachers: What does research tell us? For the Learning of Mathematics, 8(1), 8-13. 
Yenilmez, K. (2017). Öğretmen adaylarının akademik öz-yeterlikleri ve matematik öğretimine yönelik öz-yeterliklerinin bazı değişkenler açısından incelenmesi. Dicle Üniversitesi Ziya Gökalp Ĕ̈itim Fakültesi Dergisi, 29, 324-322.

Zehir, K. ve Zehir, H. (2016). İlköğretim matematik öğretmen adaylarının matematik okuryazarlığı öz-yeterlik inanç düzeylerinin çeşitli değişkenler açısından incelenmesi. Uluslararası Eğitim, Bilim ve Teknoloji Dergisi, 2(2), 104-117

\section{Summary \\ Statement of Problem}

Changes in curricula are crucial in order for learners to achieve pre-determined learning goals and adapt to the changing world (Drake, Land and Tyminski, 2014, Taber and Akpan, 2017). There has been several changes in education programs in Turkey at different times. The textbooks are prepared on the basis of teaching programs. The textbooks in education are prepared according to the teaching and learning principles indicated by the curriculum. In 2017, the curriculum of the Science Teaching Course was updated, and it was decided to apply it gradually from the fifth year of secondary school. The changes in the program necessitated the need to change the textbooks. One of the textbooks that have been revised has been the book of the 5th grade science textbook of secondary school.

Revised science textbooks started to be used in the 5th grade from 2017-2018 academic year onwards. It is believed that the opinions of teachers who use the textbooks in their lessons are important. There is also no research on this topic in the literature. Based on the literature presented above, it was found out that studies on textbooks are based on different perspectives, but that there are not adequate research looking at the appropriateness of textbooks to the curriculum. For this reason, teachers' views were taken to understand program suitability, scientific content, visual arrangements and revisions of the textbook.

\section{Method}

\section{Research Model}


The research has been structured with a qualitative approach. Descriptive analysis, one of the qualitative research types, was used in this study. In descriptive research, it is only aimed to reveal the existing situation.

\section{Universe and Sample}

Articles, books and theses published in peer-reviewed journals on the research of teacher competencies in mathematics teaching abroad and domestically constitute the universe of the research. Among these studies, the most suitable research sample has been determined. The research has been enriched with the observations and experience of the researcher in line with his profession. Thus, it was aimed to examine teacher competency areas, to contribute to the professional development of teachers, thus to have a positive effect on students' mathematics achievement and to raise awareness.

\section{Findings}

The studies examined within the scope of the study were analyzed under main headings such as field and pedagogical knowledge, education and teacher training policies at the university, teacher experience and in-service training, teacher's attitude and self-efficacy belief, and the information obtained is presented below.

\section{Area Knowledge and Pedagogical Content Knowledge}

Participants stated that teachers should have knowledge of the field and should present it to the student with a good pedagogy knowledge.

When the findings in table 1 are examined, it is understood that the mathematical knowledge of prospective teachers is generally at the operational level. Instructional explanations of teacher candidates at this level of understanding were either in the form of explaining step by step how to apply the rule, or expressions that would make the student easier to remember but could be described as "cheating" with no mathematical foundation. Only $21 \%$ of the disclosures were at the conceptual level of understanding. But about two thirds of the explanations grouped under the conceptual understanding are at the concept level. Prospective teachers making explanations at the concept level tried to model the meanings of these processes or concepts. However, because the pre-service teachers did not understand the meaning of the concepts in question sufficiently, their explanations were either above the student level or were conceptually insufficient. For example, while trying to emphasize the 
necessity of equalizing the denominator in the addition and subtraction questions of fractions, they tried to make them feel that the size of the units of the fractions did not match. But while explaining this, they highlighted the operational aspect of denominator equalization. In fact, they did not understand that the numerator equalization is creating a common unit fraction, that is, fractions equivalent to those fractions. As a result, it has been observed that, when equalizing the denominator, the multiplication of the denominator and the denominator by the same number does not realize that the amount in question is again divided by the number equal to the multiplied number. On the contrary, the preservice teachers stated that the amount multiplied by the number multiplied (Toluk-Uçar, 2010).

In some questions, preservice teachers stated that they could not explain the question, because they did not know the subject, but because they did not know why, but they could give the rule or formula directly to the student (Toluk-Uçar, 2010).

\section{Education and Teacher Training Policies Taken at the University}

The teachers stated that the education given at the university was effective on the mathematics proficiency of the teacher. It was understood from these speeches of the teachers that mathematics education given in the university plays an important role in the mathematics competencies of the classroom teachers. As a matter of fact, there are many studies emphasizing the importance of education given in universities in mathematics proficiency of the teacher (Arslan \& Özpınar, 2008; Erginer, 1995; Hill vd., 2005; Küçük vd., 2010; Peker, 2009; Smith, 2000; Ubuz, 2002 akt. Gürbüz, Erdem \& Gülburnu, 2013).

\section{Teacher Experience and In-Service Training}

They expressed that the professional experience of the teachers participating in the research positively affects teacher competence and increases student success. However, some teachers stated that as the experience increased, the proficiency of the teacher increased in every respect, while others stated that especially the teachers who approached the end of their professional life still teach their lessons with traditional methods. Here, the concept of professional experience and the concept of working year should be separated. Professional experience is obtained and improved by kneading the knowledge gained in the professional life or the situations encountered with new knowledge and developments. At this point, it cannot be said that every teacher who has worked in the teaching profession for years, as in other 
professions, is experienced. As explained above, it can be said that professional experience is an important factor affecting teachers' competence.

\section{Teacher's Attitude}

It can be said that classroom teachers' attitudes towards mathematics and their mathematics backgrounds have an impact on their proficiency and their mathematics achievement. When the opinions of the teachers in our study are examined, it can be seen that the teachers who have a positive attitude towards mathematics in their mathematics history are also successful in their professional lives. These attitudes of teachers towards mathematics directly affect students' success. As a matter of fact, it is possible to come across studies stating that the attitude of the teacher towards mathematics is reflected on the students' learning (Aiken, 1976; Brown and Baird, 1993; Bulmahn and Young, 1982; Kelly and Tomhave, 1985; Larson, 1983; Wood, 1988 akt. Gürbüz, Erdem \& Gülburnu, 2013).

\section{Self-efficacy Belief}

In the self-efficacy sub-dimension of the scale prepared for the purpose of determining pre-service teachers' self-efficacy beliefs related to mathematics teaching, if all the items were marked as undecided, a total of 42 points could be obtained, if the items in the coping behavior sub-dimension were all undecided, a total of 30 points and a total of 72 points in the overall total .It is clearly seen in table 2 that the arithmetic averages are above these scores. This means that pre-service teachers' positive self-efficacy beliefs are higher than the total score average that can be obtained from the scale. It can be concluded that the arithmetic average is close to high scores, preservice teachers developed their self-efficacy beliefs towards mathematics during their undergraduate education and reached a remarkable level at the end of 4th grade (Aksu, 2008).

\section{Discussion and Conclusion}

It can be said that a teacher who has a good level of field knowledge and who does not know how to transfer this information to students will not be able to perform a good education. As a matter of fact, all the participants agreed that it is very important for the teacher to have sufficient knowledge of the field, as well as to convey this knowledge well to the learners (Gürbüz, Erdem \& Gülburnu, 2013). 
The majority of the explanations made by the preservice teachers were in the form of repetition of the rules of the procedures. In addition to explaining how to apply the rules in the teacher candidates' explanations, it was determined that they also included explanations without any mathematical basis. While very few teacher candidates can explain at a conceptual level, almost none of them used the meanings and reasons underlying the rules of the processes. In addition, it has been observed that teacher candidates have good algorithm and rule knowledge. However, it was observed that they had some misconceptions about the number zero. Some pre-service teachers stated that zero is not a number but a symbol (Toluk-Uçar, 2010).

The participants stated that the education given at the university was effective on the mathematics proficiency of the teacher. The teachers who gave opinions in this direction stated that the mathematics education given in the university and the mathematics education they carried out in their professional life were very different from each other and they received more theoretical mathematics education in the university. In order to prevent this conflict, it has been revealed that pre-service teachers need to teach more in real classroom settings during their university years (Gürbüz, Erdem \& Gülburnu, 2013).

The ability of teachers to perform a successful education process depends on their selfefficacy beliefs. When studies on teacher self-efficacy beliefs are examined, teachers with high self-efficacy beliefs are more successful in keeping their student success and motivation higher, where they are more planned, organized and conscious, willing to look for new approaches to meet the needs of students, use positive approaches in classroom management. They are emphasized (Akbaş \& Çelikkaleli, 2006; Başer, 2007; Ekici, 2006; Günhan Akbaş \& Çelikkaleli, 2006; Hamurcu, 2006, Umay, 2002, akt. Aksu, 2008). 